\title{
Current trends of Hepatitis $C$ virus genotypes and associated risk factors in hemophilia patients in Pakistan
}

\author{
Yaqoob, M. ${ }^{1}$, Khan, S. ${ }^{*}$, Atta, S. ${ }^{2}$ and Khan, S.N. ${ }^{3}$ \\ ${ }^{1}$ Department of Zoology, University of Peshawar Khyber Pakhtunkwa Pakistan \\ ${ }^{2}$ Department of Zoology, Islamia College Peshawar Khyber Pakhtunkwa Pakistan \\ ${ }^{3}$ Department of Zoology, Kohat University of Science and Technology Kohat Khyber Pakhtunkwa Pakistan \\ *Corresponding author e-mail: sanaullahkhan@uop.edu.pk \\ Received 31 January 2020; received in revised form 6 July 2020; accepted 7 July 2020
}

\begin{abstract}
Hemophilia is a rare bleeding disorder that needs plasma or clotting factor concentrate transfusion. Therefore chances of blood-borne pathogens like HCV transmission increase due to high prevalence in healthy donors. This study was aimed to determine the prevalence of HCV genotypes and associated risk factors in hemophilia patients of Khyber Pakhtunkhwa, Pakistan. Blood samples and data were collected from 672 hemophiliacs after proper consent obtained from each patient. Samples were analyzed for anti-HCV, HCV RNA and HCV genotype/s detection. Of the total, $22.32 \%$ (150) were anti-HCV positive, of which HCV RNA was detected in $18.45 \%$ (124) individuals. HCV genotype 3a was found with significantly higher prevalence $(\mathrm{p}<0.05)(19.35 \%)$ as compared to $2 \mathrm{a}(16.13 \%)$ and $1 \mathrm{a}(12.90 \%)$. HCV-3b and HCV-4 were found each in $3.22 \%$ samples. Dual infection of genotypes was found in $22.58 \%$ of individuals and $22.58 \%$ HCV RNA positive sampels were not typed. A total of 572 (85.12\%) subjects had hemophilia A and 100 (14.88\%) had hemophilia B. In hemophiliacs A the most dominant genotype was 3 a (19.27\%) while in hemophilia B, genotype 1a was prevalent (26.67\%). Whole blood and plasma transfusion were observed as the main risk factors of HCV. It is concluded that HCV genotype $3 \mathrm{a}$ and $2 \mathrm{a}$ are prevalent in hemophilia patients of Khyber Pakhtunkhwa Pakistan and the main risk factor observed was an unscreened whole blood transfusion.
\end{abstract}

\section{INTRODUCTION}

Hepatitis C virus (HCV) infection is a major global public health problem particularly in multi transfused patients like hemophiliacs. Hemophilia is a rare $\mathrm{X}$-linked recessive bleeding disorder caused by partial or complete lack of clotting factor VIII (hemophilia A) or factor IX (hemophilia B) and the affected individuals need blood plasma or clotting factor concentrate transfusion (Srivastava et al., 2013). The prevalence of hemophilia is about 1 per 5000-10000 male live births, with about 85\% hemophilia A and 15\% hemophilia B across the globe (Bowen, 2002). HCV transmits through intravenous drug use, hemodialysis, needle stick injuries, unprotected sex, surgery, and blood and blood product transfusion (Ghany et al., 2009). Blood and blood product transfusion is common in genetically transmitted blood disorders like thalassemia and hemophilia and the chances of transfusion-transmitted infections like HCV increases due to frequent transfusion (Alter and Klein, 2008). In developing countries like Pakistan where blood screening facilities are not widely available, chances of bloodborne pathogens increase due to its high prevalence in the general public population (WHO, 2011).

HCV is an enveloped virus with a positive-sense single-stranded RNA genome. Due to poor fidelity of RNA-dependent-RNApolymerase, the virus exhibits a high level of genetic diversity and leads to varying genotypes (1-6) and many subtypes distributed variably in different regions 
across the globe (Moradpour et al., 2007). Distributions of HCV genotypes are highly variable among hemophiliacs and most of the studies reflect the genotypes distribution to the general public population. HCV genotypes 1, 2 and 3, are the more dominant North America, genotype 4 in the Middle East and North Africa and genotype 5 in South Africa (Giangrande, 1998) while in European countries more than one genotype exists especially among hemophiliacs (Sereno et $a l ., 2009)$. HCV genotype $1 \mathrm{a}$ and $3 \mathrm{a}$ are common in hemophiliacs of Iran (SamimiRad et al., 2012), while in India the most prevalent genotype is $3 \mathrm{a}$ (Rehan et al., 2011). In Pakistan, HCV genotype 3 is the most prevalent followed by genotype 2 and 1 in the general population (Khan et al., 2014; Waqas et al., 2015). Some studies from parts of the country reported HCV genotype 1 and 3 a from Punjab province (Waheed $e t$ al., 2011).

The province Khyber Pakhtunkhwa of Pakistan has about 3000 hemophilia patients who have been registered in various blood transfusions providing organizations located in the capital city Peshawar (Nazir et al., 2014). Data regarding the prevalence of $\mathrm{HCV}$ and HCV genotypes and associated risk factors in this area is scarce. This study aimed to evaluate the prevalence and risk factors of HCV genotypes in hemophilia patients of Khyber Pakhtunkhwa Pakistan.

\section{MATERIALS AND METHODS}

\section{Study area and study population}

This study was performed in the capital city of Khyber Pakhtunkhwa province Pakistan. The total area of the province is $101741 \mathrm{~km}^{2}$ having a population of 35.53 million with an average density of $350 / \mathrm{km}^{2}$. This area is one of the important zones located in the northwestern part of the country along the international border with Afghanistan (Fig. 1). Since major health facilities like tertiary care hospitals and blood donation centers are located in Peshawar, therefore, hemophiliacs had frequently visited the blood centers there to receive hemotherapy. Hemophiliacs belonged to various parts of the province were enrolled in the study who visited various blood transfusions providing organizations located in Peshawar, Pakistan.

\section{Ethical approval}

This study was approved by the Advanced Studies and Research Board (ASRB), and ethical committee Centre of Biotechnology and Microbiology University of Peshawar Pakistan.

\section{Data and Samples collection}

Data was collected using a predesigned questionnaire from patients or their parents after written consent including the history of hepatitis in family, whole blood or plasma transfusion, factor concentrate transfusion, type of hemophilia, the severity of the disease, etc. Blood ( $3 \mathrm{~mL}$ ) was collected from patients and sera were separated and stored at $-20^{\circ} \mathrm{C}$ at Molecular Biology and Virology Laboratory Department of Zoology University of Peshawar Khyber Pakhtunkhwa Pakistan for further process.

\section{Anti-HCV screening}

Sera samples were screened for anti-HCV using ICT device kit (Accurate Diagnostic, Canada), according to manufacturer instructions.

\section{HCV RNA isolation and amplification}

RNA was isolated from anti-HCV positive sera using a nucleic acid isolation kit (Favorgen, USA) as per manufacturer protocol. cDNA was synthesized of the 5'UTR of HCV genome using antisense primer and 200U of M-MLV RTase (Invitrogen, USA). cDNA was then amplified in nested PCR with two sets of 5'UTR specific primers (outer and inner) using $5 \mathrm{U}$ of Taq DNA polymerase (ThermoFischer, USA). A reaction mixture $(20 \mu \mathrm{L})$ for nested PCR was consisted of $2 \mu \mathrm{l}$ of 10X PCR buffer, $2.5 \mu \mathrm{l}$ of $25 \mathrm{mmol}$ $\mathrm{MgCl}_{2}, 1 \mu \mathrm{L}$ of $10 \mathrm{mM}$ dNTPs, $1 \mu \mathrm{L}$ Taq DNA polymerase (2UI/uL), $2 \mu \mathrm{L}$ of previous round PCR product, and $1 \mu \mathrm{L}$ each primer $(10 \mathrm{pmol})$. The reaction program was composed of 25 cycles with the following conditions: $94^{\circ} \mathrm{C}$ for 30 seconds, $55^{\circ} \mathrm{C}$ for 40 seconds, and $72^{\circ} \mathrm{C}$ for 40 seconds with an initial denaturation 


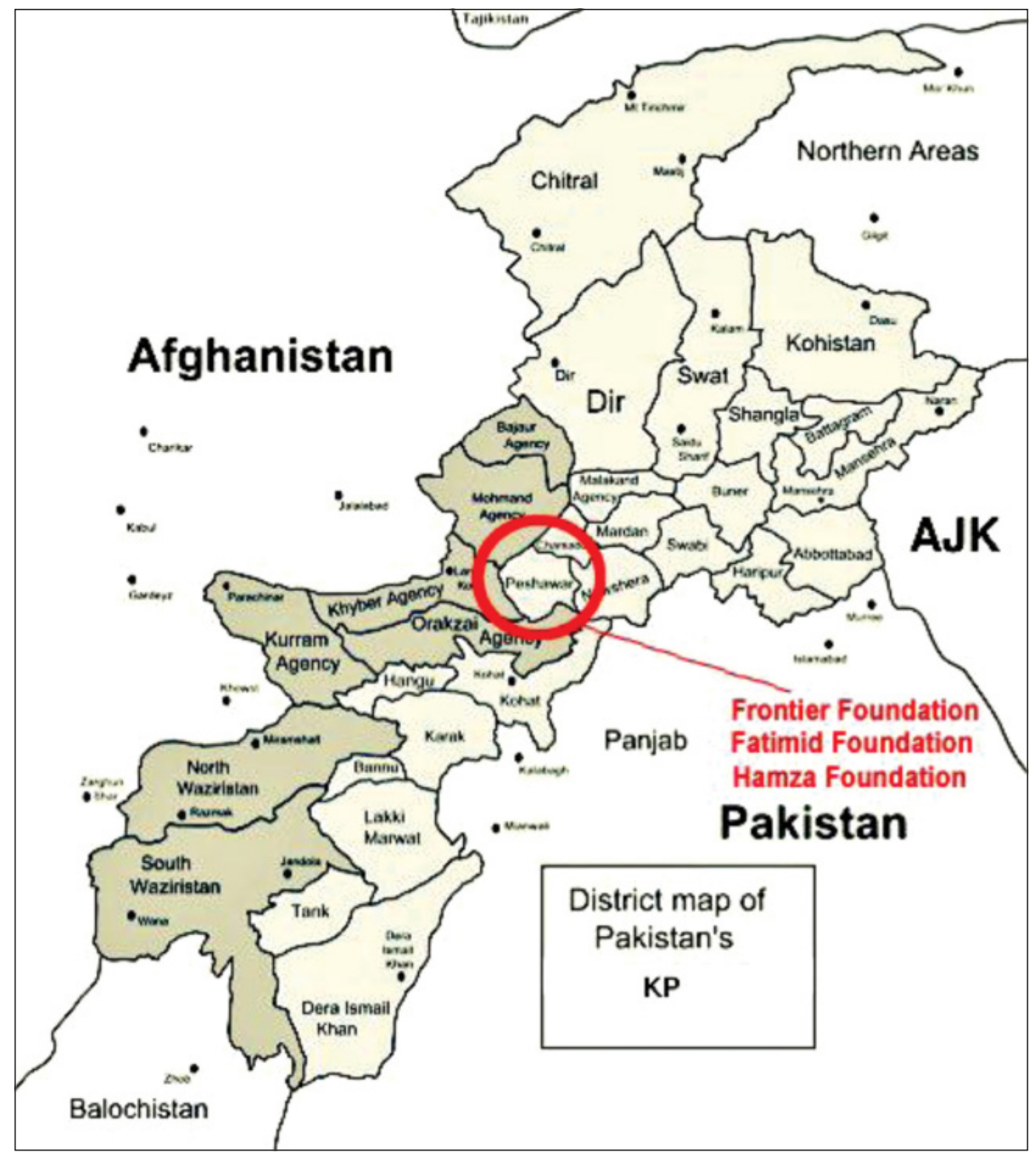

Figure 1. The geographical location of the study area (Khyber Pakhtunkhwa).

at $94^{\circ} \mathrm{C}$ for 5 minutes and a final extension at $72^{\circ} \mathrm{C}$ for 10 minutes.

\section{HCV genotyping}

cDNA was synthesized from extracted RNA using antisense primer specific for the HCV core region and 200U of M-MLV RTase (Invitrogen, USA) according to the manufacturer protocol. cDNA was amplified with a pair of core region-specific primers and Taq DNA polymerase (Fermentas USA). Two aliquots of reaction mixtures were prepared, different in antisense primers (subtypespecific primers). The anti-sense primers of one mix were $1 b, 2 a$, ID- $8,2 b, 3 b$ and the other were $1 \mathrm{a}, 3 \mathrm{a}, 4,5 \mathrm{a}, 6 \mathrm{a}$. The reaction was processed as mentioned by Ohno et al. (1997).

\section{Electrophoresis}

PCR amplified product was electrophoresed on $2 \%$ agarose gel along with $50 \mathrm{bp}$ DNA ladder marker (Fermentas, USA) and visualized under UV-transilluminators. 


\section{Statistical analyses}

Some variables of the study were presented in percentages (\%). Chi-square $(\chi 2)$ test was used for data analysis and measuring the association between variables and p-value of 0.05 or less was considered significant.

\section{RESULT}

\section{Demographic characteristics of patients}

The baseline characteristics of hemophiliacs of this study are shown in Table 1. Of the total 672 hemophiliacs included were of age ranged from 3-57 years. Of these, 68 patients were of severe hemophilia (clotting factor level $<1 \%$ ), 540 of moderate (clotting factor level 1-5\%), and 64 of mild (clotting factor level 6-50\%) hemophilia. 572 were suffered of hemophilia A and 100 (14.88\%) of hemophilia B. Most of the patients had a history of different risk factors like whole blood, plasma and factor concentrate transfusion, surgery, circumcision, etc. Most of the patients had multiple transfusion of plasma or factors' concentrate.

\section{HCV prevalence among hemophiliacs}

Of the total, HCV antibodies were detected in $150(22.32 \%)$ patients. The rate of anti-HCV was more in patients with hemophilia-A. A high prevalence of anti-HCV was observed in severe hemophiliacs. HCV RNA was detected in 124 (18.45\%), in samples positive for anti-HCV. Higher detection of HCV RNA was recorded in patients with hemophilia-A. The prevalence of HCV RNA was found higher in patients with severe hemophilia as compared to the moderate and mild type of disease. No significant difference $(\mathrm{P}>0.05)$ was seen between anti-HCV and HCV RNA positive patients and disease type and severity (Table 2).

Table 1. Characteristics of patients with hemophilia $(\mathrm{N}=672)$

\begin{tabular}{lc}
\hline Variables & Values N (\%) \\
\hline Age range & $3-57$ years \\
Hemophilia type & \\
Hem-A & $572(85.12)$ \\
Hem-B & $100(14.88)$ \\
Severity of Hemophilia & \\
Sever & $68(10.12)$ \\
Moderate & $540(80.36)$ \\
Mild & $64(9.52)$ \\
Main risk factors & \\
Blood and plasma transfusion & $160(23.8)$ \\
Plasma and factor concentrate transfusion & $115(17.11)$ \\
Plasma transfusion & $245(36.45)$ \\
Factor concentrate transfusion & $60(8.9)$ \\
Dental and general surgery & $45(6.7)$ \\
Others & $47(6.9)$ \\
\hline
\end{tabular}

Table 2. Distribution of Anti-HCV and HCV RNA among hemophilia patients

\begin{tabular}{|c|c|c|c|c|c|}
\hline \multirow{2}{*}{ Hemophilia types $(\mathrm{N})$} & \multicolumn{2}{|c|}{ Anti HCV } & \multicolumn{2}{|c|}{ HCV RNA } & \multirow{2}{*}{ P-value } \\
\hline & +ve N (\%) & -ve N (\%) & +ve N (\%) & -ve N (\%) & \\
\hline Hem A (572) & $134(23.43)$ & $438(76.57)$ & $109(19.06)$ & $463(80.94)$ & \multirow{2}{*}{0.709} \\
\hline Hem B (100) & $16(16)$ & $84(84)$ & $15(15)$ & $85(85)$ & \\
\hline \multicolumn{6}{|l|}{ Disease severity $(\mathrm{N})$} \\
\hline Severe (68) & $37(54.4)$ & $31(45.6)$ & 28 (41.18) & $40(58.82)$ & \multirow{3}{*}{0.718} \\
\hline Moderate (540) & $95(17.6)$ & $445(82.4)$ & $84(15.6)$ & $456(84.4)$ & \\
\hline Mild (64) & $18(28.12)$ & $46(71.88)$ & $12(18.75)$ & $52(81.25)$ & \\
\hline
\end{tabular}




\section{HCV and associated risk factors}

Different risk factors were analyzed for $\mathrm{HCV}$ infection in hemophiliacs shown in Table 3. In both types of hemophilia, local transfusion of unscreened blood and plasma were the main risk factors of HCV infection. Statistically, no significant associations were found $(\mathrm{P}>0.05)$.

HCV Genotypes in the Study Population Of the total 124 HCV RNA positive samples, five different genotypes were detected. Overall, genotype 3a (24/124) was significantly higher $(\mathrm{P}<0.05)$ followed by $2 \mathrm{a}(20 /$ 124) and 1a (16/124). Each HCV 3b and 4 genotype were found in 4/124 samples. Dual HCV infection 2a/3a (8/28), 3b/3a (16/
28), $2 \mathrm{a} / 4(4 / 28)$ were also observed. Of the total, 28 samples were found untypable (Fig. 2).

\section{HCV genotypes distribution among hemophiliacs}

The distribution of HCV genotypes in both types of hemophilia and disease severity was shown in Table 4. In hemophilia A the most dominant genotype was 3a (21/109) followed by $2 \mathrm{a}$ and $1 \mathrm{a}(20 / 109)$ and (12/109) respectively. Among patients with hemophilia B, genotype la was the most prevalent (4/15) followed by $3 \mathrm{a}(3 / 15)$. In severe hemophilia $3 \mathrm{a}(16 / 28)$ while in that of moderate $2 \mathrm{a}(12 / 84)$ and mild hemophilia the most dominant genotype was $1 \mathrm{a}(8 / 12)$.

Table 3. HCV prevalence and associated risk factors

\begin{tabular}{|c|c|c|c|c|c|c|c|}
\hline \multirow{2}{*}{ Risk factors } & \multicolumn{3}{|c|}{ Hem A } & \multicolumn{3}{|c|}{ Hem B } & \multirow{2}{*}{$\mathrm{P}$-value } \\
\hline & $\mathrm{N}$ & +ve N (\%) & -ve N (\%) & $\mathrm{N}$ & +ve N (\%) & -ve N (\%) & \\
\hline Blood+plasma & 120 & 46 (38.33) & 74 (61.67) & 40 & $7(17.5)$ & $33(82.5)$ & \multirow{6}{*}{0.839} \\
\hline $\begin{array}{l}\text { Plasma+factor } \\
\text { concentrate }\end{array}$ & 103 & $16(15.53)$ & 87 (84.47) & 12 & $3(25)$ & $9(75)$ & \\
\hline Only plasma & 225 & 37 (16.44) & $188(83.56)$ & 20 & $4(20)$ & $16(80)$ & \\
\hline Only factor & 42 & $4(9.52)$ & 38 (90.48) & 18 & - & $18(100)$ & \\
\hline $\begin{array}{l}\text { Dental+general } \\
\text { surgery }\end{array}$ & 42 & - & $42(100)$ & 3 & - & $3(100)$ & \\
\hline Others & 40 & $6(15)$ & $34(85)$ & 7 & $1(14.28)$ & $6(85.72)$ & \\
\hline
\end{tabular}

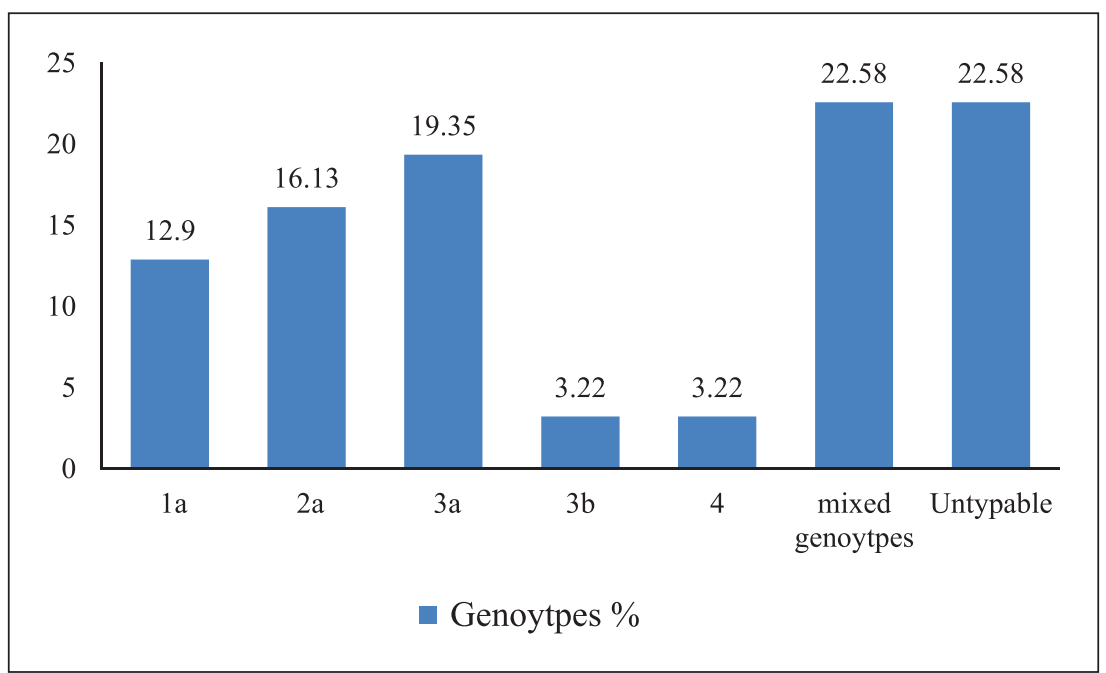

Figure 2. Distribution of HCV genotypes among the patients. 
Table 4. Prevalence of HCV genotypes in HCV RNA positive samples

\begin{tabular}{|c|c|c|c|c|c|c|c|}
\hline Parameter & $\begin{array}{c}1 \mathrm{a} \\
\mathrm{N}(\%)\end{array}$ & $\begin{array}{c}2 \mathrm{a} \\
\mathrm{N}(\%)\end{array}$ & $\begin{array}{c}3 \mathrm{a} \\
\mathrm{N}(\%)\end{array}$ & $\begin{array}{c}3 b \\
\text { N (\%) }\end{array}$ & $\begin{array}{c}4 \\
\text { N (\%) }\end{array}$ & $\begin{array}{l}\text { Mixed } \\
\text { N (\%) }\end{array}$ & $\begin{array}{c}\text { Untypable } \\
\text { N (\%) }\end{array}$ \\
\hline \multicolumn{8}{|l|}{ Hem-type (N) } \\
\hline Hem-A (109) & $12(11.01)$ & $20(18.35)$ & $21(19.27)$ & $4(3.67)$ & $4(3.67)$ & $2018.35)$ & $28(25.69)$ \\
\hline Hem-B (15) & $4(26.67)$ & - & $3(20)$ & - & - & $8(53.33)$ & - \\
\hline \multicolumn{8}{|l|}{ Severity of disease } \\
\hline Sever (28) & - & $4(14.29)$ & $16(57.14)$ & - & - & - & $8(28.57)$ \\
\hline Moderate (84) & $8(9.52)$ & $12(14.28)$ & $8(9.52)$ & $4(4.76)$ & $4(4.76)$ & $28(33.33)$ & $20(23.81)$ \\
\hline Mild (12) & $8(66.7)$ & $4(33.33)$ & - & - & - & - & - \\
\hline
\end{tabular}

\section{DISCUSSION}

Transfusion transmitted diseases are the major public health problems particularly in multi transfused patients like hemophiliacs and are the most important complications which lead to chronic conditions cause high morbidity and mortality across the world. Of this hep-C is the most important due to high prevalence in the general public population (Karimi et $a l .$, 2002) and was frequently observed in hemophilia patients treated with clotting factor concentrates before the 1980s (Choi, 2014). Patients with hemophilia have a high risk of acquiring $\mathrm{HCV}$ and other pathogens like HBV and HIV due to frequent blood or blood products transfusion (Rezvan et al., 2007) mainly in regions with poor blood screening practices and high prevalence among blood donors (De Paula et al., 2005).

In the study population five different $\mathrm{HCV}$ genotypes 1a, 2a, 3a, 3b, and 4 were detected. Highest prevalence of genotype 3 a was found in study population (19.35\%) followed by $2 \mathrm{a}$ (16.13\%), 1a (12.90\%), 3b and 4 (3.22\% each) and (22.58\%) respectively with some mixed genotypes as $2 \mathrm{a} / 3 \mathrm{a} 8$ (6.25\%), 3b/3a 16 (12.5\%), 2a/4 4 (3.12\%) while (22.58\%) were untypable. Prevalence of HCV genotypes in hemophilia patients of Khyber Pakhtunkwa province also determine their distribution in the general public. This study is not in line with studies conducted in Latin America (Martins et al., 2000) and the USA, Japan, and Brazil where HCV genotype 1 was prevalent (Sereno et al., 2009). In most of the European countries like Italy reported the distribution of genotype 1 and 2 there (Oliveira et al., 1999). Our study has similar findings to that reported from Iran (Amini et al., 2009; Samimi-Rad et al., 2012). Similar findings were found by Rehan et al. (2011) in India and Alfaresi, (2011) in the UAE.

In our study genotype, $3 \mathrm{a}$ is more common among the study population reflecting the overall distribution of $\mathrm{HCV}$ genotype $3 \mathrm{a}$ in the general population of Pakistan (Ali et al., 2010). Studies conducted in various regions of Pakistan in hemophilia patients showed that HCV genotype $3 \mathrm{a}$ is common (Khokhar et al., 2003).

The presence of untyped samples indicates that some novel genotypes may be present in this population not detected by the genotyping method used in this study or maybe with low viral load. The prevalence of mixed genotypes of the current findings are similar to the study of Zoulim (1999), showed that hemophilia patients are more susceptible to reinfected several times with different HCV genotypes and subtypes due to frequent plasma and factor concentrate transfusion derived from donors blood. The present study suggested that the distribution of HCV genotypes in the hemophilia population of Khyber Pakhtunkhwa reflected the prevalence of HCV genotypes in the general public.

It is obvious from the findings of the present study that whole blood, plasma and factor concentrate transfusion were the main risks of HCV transmission in hemophilia patients. Similar findings of Asif et al. (2009) mentioned that plasma transfusion was the main risk of HCV in hemophilia population. A study conducted in Iran by Hajiani et al. (2006) was related to current study suggested that plasma transfusion was the leading risk 
factor for HCV transmission in hemophilia patients treated with regular plasma transfusion.

\section{CONCLUSIONS}

A high prevalence of HCV was detected in hemophilia patients of Khyber Pakhtunkhwa province and genotype $2 \mathrm{a}$ and $3 \mathrm{a}$ were widely distributed in these patients. Whole blood and poorly screened plasma transfusions are the important risk factors of HCV.

Acknowledgment. The authors acknowledge Pakistan Science Foundation Islamabad Pakistan for financial support under Project No. Med-283.

\section{REFERENCES}

Alfaresi, M.S. (2011). Prevalence of hepatitis $\mathrm{C}$ virus (HCV) genotypes among positive UAE patients. Molecular Biology Reports 38(4): 2719-2722.

Ali, A., Ahmed, H. \& Idrees, M. (2010). Molecular epidemiology of Hepatitis C virus genotypes in Khyber Pakhtunkhwa of Pakistan. Virology Journal 7(1): 203.

Alter, H.J. \& Klein, H.G. (2008). The hazards of blood transfusion in historical perspective. Blood 112: 2617-26.

Amini, S., Abadi, M., Alavian, S.M., Joulaie, M. \& Ahmadipour, M.H. (2009). Distribution of hepatitis $\mathrm{C}$ virus genotypes in Iran: a population based study. Hepatitis Monthly 9: 95-102.

Asif, N., Zafar, T., Hassan, K. \& Naseem, L. (2009). Seroprevalence Anti HCV Antibodies, HCV- RNA and its Genotypes among Patients of Hemophilia, at Hemophilia Treatment Centre Pakistan Institute of Medical Sciences, Islamabad. International Journal of Pathology 7(2): 84-87.

Bowen, D.J. (2002). Haemophilia A and haemophilia B: molecular insights. Molecular Pathology 55(2): 127-44.

Choi, E.J. (2014). Management of hemophilia in Korea: the past, present, and future. Blood Research 49(3): 144-145. de Paula, E.V., Gonçales, N.S., Xueref, S. Addas-Carvalho, M., Gilli, S.C., Angerami, R.N., Veríssimo, M.P. \& Gonçales, F.L., Jr. (2005). Transfusion-transmitted infections among multi-transfused patients in Brazil. Journal of Clinical Virology 34 Suppl 2: S27-32.

Ghany, M.G., Strader, D.B., Thomas, D.L. \& Seeff, L.B. (2009). Diagnosis, management, and treatment of hepatitis C: an update. Hepatology 49: 1335-74.

Giangrande, P.L.F. (1998). Review: Hepatitis in haemophilia. British Journal of Haematology 103: 1-9.

Hajiani, E., Hashemi, J., Masjedizadeh, R., Shayesteh, A.A.M., Idani, E. \& Rajabi, T. (2006). Seroepidemiology of hepatitis $\mathrm{C}$ and its risk factors in Khuzestan Province, south-west of Iran: a casecontrol study. World J Gastroenterol 12(30): 4884-7.

Karimi, M., Yarmohammadi, H., Ardeshiri, R. \& Yarmohammadi, H. (2002). Inherited coagulation disorders in southern Iran. Haemophilia 8: 740-744.

Khan, N., Akmal, M., Hayat, M., Umar, M., Ullah, A., Ahmed, I., Rahim, K., Ali, S., Bahadar, S. \& Saleha, S. (2014). Geographic distribution of hepatitis $\mathrm{C}$ virus genotypes in Pakistan. Hepatitis Monthly 14: e20299.

Khokhar, N., Asif, N. \& Khokhar, O.S. (2003). Serotype 3 is most common hepatitis C serotype in Pakistan, however, significant numbers are untypeable. Hepatology 38 : 270-271.

Martins, R.M., Barbosa, A.P., Oliveira, J.M., Vanderburgh, B. \& Yoshida, C.F. (2000). Genotype analysis of hepatitis $\mathrm{C}$ virus in Brazilian hemophiliacs and blood donors. Vox Sanguinis 78: 255.

Moradpour, D., Penin, F. \& Rice, C.M. (2007). Replication of hepatitis C virus. Nature Review Microbiology 5: 453-463.

Nazir, S., Faraz, A., Shahzad, N., Ali, N., Khan, M.A., Iqbal, M. \& Sabzwari, J. (2014). Prevalence of HCV in $\beta$-thalassemia major patients visiting tertiary care hospitals in Lahore-Pakistan. Advancements in Life Sciences 1(4): 197-201. 
Ohno, O., Mizokami, M., Wu, R.R., Saleh, M.G., Ohba, K., Orito, E., Mukaide, M., Williams, R. \& Lau, J.Y. (1997). New Hepatitis C Virus (HCV) genotyping system that allows for identification of HCV Genotypes 1a, 1b, 2a, 2b, 3a, 3b, 4, $5 \mathrm{a}$, and 6a. Journal of Clinical Microbiology 35: 201-202.

Oliveira, G.C., Carmo, M.O.C., Rocha, M.O., Silva, A.T., Lima, M.D.C., Guimarães. \& Correa-Oliveira, R. (1999). Hepatitis C virus genotypes in hemophiliacs in the state of Minas Gerais, Brazil. Transfusion 39: 1194-1199.

Rehan, H.S., Manak, S., Yadav, M., Deepinder, Chopra, D. \& Wardhan, N. (2011). Diversity of genotype and mode of spread of hepatitis C virus in Northern India. Saudi Journal of Gastroenterology 17(4): 241244.

Rezvan, H., Abolghassemi, H. \& Kafiabad, S.A. (2007). Transfusion-transmitted infections among multitransfused patients in Iran: a review. Transfusion Medicine 17(6): 425-33.

Samimi-Rad, K., Toosi, M.N., Masoudi-Nejad, A., Najafi, A., Rahimnia, R., Asgari, F., Shabestari, A.N., Hassanpour, G., Alavian, S. \& Asgari, F. (2012). Molecular epidemiology of hepatitis $\mathrm{C}$ virus among injection drug users in Iran: a slight change inprevalence of HCV genotypes over time. Archive of Virology 157(10): 1959-1965.
Sereno, S., Perinelli, P. \& Laghi, V. (2009). Changes in the preva-lence of hepatitis $\mathrm{C}$ virus genotype among Italian injection drug usersrelation to period of injection started. Journal of Clinical Virology 45: 354-357.

Srivastava, A., Brewer, A.K. \& MauserBunschoten, E.P. (2013). Treatment Guidelines Working Group on Behalf of The World Federation of Hemophilia. Guidlines for the management of hemophilia. Haemophilia 19: e1-47.

Waheed, Y., Shafi, T., Safi, S.Z. \& Qadri, I. (2011). Hepatitis C virus in Pakistan: a systematic review of prevalence, genotypes and risk factors. World Journal of Gastroenterology 15(45): 5647-53.

Waqas, M., Parveen, F., Waqar, M., Ali, A., Khan, M.A., Wasim, M., Khan, A.U., Rehman, Z., Ahmad, T., Shereen, M.A. \& Nawaz, R. (2015). Distribution Pattern of Various Genotypes of HCV Circulating in District Mardan, Khyber Pakhtunkhwa, Pakistan. Advanced Biology Research 9(2): 69-74.

World Health Organisation. (2011). Global Database on Blood Safety Reports. https://www.who.int/bloodsafety/ global_database/GDBSReport20042005.pdf?ua=1. Accessed on 12.08.2019.

Zoulim, F. (1999). Hepatitis C virus infection in special groups. Journal of Hepatology 31(Suppl 1):130-5. 